Supporting Information

\title{
Sustained delivery of carfilzomib by tannic acid-based nanocapsules helps develop antitumor immunity
}

Maie S. Taha ${ }^{1,2}$, Gregory M. Cresswell ${ }^{3}$, Joonyoung Park ${ }^{1}$, Wooin Lee ${ }^{4}$, Timothy L. Ratliff ${ }^{3}$, Yoon $\mathrm{Yeo}^{1,5 *}$

${ }^{1}$ Department of Industrial and Physical Pharmacy, Purdue University, 575 Stadium Mall Drive, West Lafayette, IN 47907, USA

${ }^{2}$ Department of Pharmaceutics and Industrial Pharmacy, Faculty of Pharmacy, Cairo University, Cairo 11562, Egypt

${ }^{3}$ Department of Comparative Pathobiology and Purdue University Center for Cancer Research, 625 Harrison Street, West Lafayette, IN, 47907, USA

${ }^{4}$ College of Pharmacy and Research Institute of Pharmaceutical Sciences, Seoul National University, Seoul, 08826, Republic of Korea

${ }^{5}$ Weldon School of Biomedical Engineering, Purdue University, West Lafayette, IN 47907, USA

* Corresponding author:

Yoon Yeo, Ph.D.

Phone: 1.765.496.9608

Fax: 1.765.494.6545

E-mail: yyeo@purdue.edu

Detailed description of Materials and Methods

Tables S1 to S2

Figures S1 to S15 


\section{Materials and Methods}

\section{Materials}

Carfilzomib (CFZ) was purchased from Shenzhen Chemical Co. LTD. (Shanghai, China). Tannic acid, iron chloride, 2-hydroxypropyl- $\beta$-cyclodextrin, human serum albumin $(\geq 96 \%$ agarose gel electrophoresis) and Irgacure 2959 were purchased from Sigma-Aldrich (St. Louis, MO, USA). Polyethyleneglycol dimethylacrylate (PEGDA, MW: $3400 \mathrm{Da}$ ) was purchased from Alfa Aesar (Haverhill, MA, USA). Mouse interferon-gamma (IFN- $\gamma$ ) ELISA kit was purchased from Invitrogen (Eugene, OR, USA). GM-CSF was purchased from PeproTech (Rock Hill, NJ, USA). Purified rat anti-mouse CD16/CD32 (Fc block), APC anti-mouse CD11c, FITC antimouse CD40, PE anti-mouse CD86, FITC anti-mouse CD4, APC anti-mouse CD8a, and Zombie Violet were purchased from BioLegend (San Diego, CA, USA). AH1 peptide was purchased from Anaspec (Fremont, CA, USA). All other materials were of analytical grade and purchased from Thermo Fisher Scientific (Waltham, MA, USA).

\section{TA/Fe ${ }^{3+}$-stabilized CFZ nanocore preparation and albumin coating}

CFZ was mixed with TA in $30 \mu \mathrm{L}$ ethanol at a CFZ to TA molar ratio of 2.4 . To this mixture, $10 \mathrm{~mL}$ water containing $100 \mu \mathrm{g} \mathrm{FeCl} 3$ (molar ratio of TA to $\mathrm{Fe}^{3+}: 1.1$ ) was added and mixed briefly with simple agitation to form nanocapsules. The particles were centrifugated at 43,400 ref for $20 \mathrm{~min}$ at $4{ }^{\circ} \mathrm{C}$ to remove excess TA and $\mathrm{FeCl}_{3}$. The formed nanocapsules were called CFZ-pTA, where pTA stands for polymerized tannic acid crosslinked via $\mathrm{Fe}^{3+}$. The CFZpTA nanocapsules were further incubated in albumin solution $(2 \mathrm{mg} / \mathrm{mL})$ in water at CFZ-pTA to albumin weight ratio of $1: 2$, with mild rotation at room temperature (RT) for $4 \mathrm{~h}$. The particles were centrifuged at $43,400 \mathrm{rcf}$ for $20 \mathrm{~min}$ at $4^{\circ} \mathrm{C}$ to remove unadsorbed albumin and washed twice by repeated centrifugation. The albumin-coated CFZ-pTA nanocapsules were called CFZpTA-alb. As controls, pTA (TA/Fe ${ }^{3+}$ nanoassemblies) and pTA-alb (albumin-coated pTA) were prepared in the same method as above omitting CFZ. Bare CFZ particles (with no pTA) were prepared by adding water to ethanolic solution of CFZ. The particles were suspended in water and stored at $4{ }^{\circ} \mathrm{C}$.

\section{Nanocapsule characterization}

Particle size and surface charge

The hydrodynamic diameter (z-ave), polydispersity index (PDI) and zeta potential of particles were measured by dynamic light scattering (DLS) in sodium phosphate buffer $(10 \mathrm{mM}$, pH 7.4) using a Zetasizer Nano-ZS90 (Malvern Instruments, Worcestershire, UK).

\section{Morphology}

Particle morphology was examined by transmission electron microscopy (TEM). An aqueous suspension of freshly prepared particles was placed on a carbon coated copper grid (400 mesh), negatively stained with $1 \%$ uranyl acetate and allowed to dry in air. The dried grid was examined under an FEI Tecnai T20 transmission electron microscope (Hillsboro, OR, USA). To visualize the capsule structure of CFZ-pTA, the core part of the particles was dissolved in PBS containing $0.2 \%$ Tween 80 for $6 \mathrm{~h}$. The particles were collected by centrifugation, resuspended in water, put on the grid and processed as above. 


\section{CFZ and TA contents in CFZ-pTA}

The CFZ content in CFZ-pTA was determined by C18 reverse phase HPLC $(25 \mathrm{~cm} \times 4.6$ $\mathrm{mm}$, particle size: $5 \mu \mathrm{m})$. CFZ-pTA with a premeasured mass was added to an aqueous solution (pH 7.4) containing ethylenediaminetetraacetic acid (EDTA) $\left(100 \mathrm{mM}\right.$, to remove $\mathrm{Fe}^{3+}$ ) and urea solution (5M, to disrupt hydrogen bonding between TA and CFZ), mixed briefly by vortexing, and mixed with additional acetonitrile (to dissolve CFZ), making the final particle concentration $\sim 50 \mu \mathrm{g} / \mathrm{mL}$. The resulting solution was filtered on $0.45 \mu \mathrm{m}$ syringe filter prior to analysis. CFZ was analyzed according to the previously reported method $^{1}$ with slight modifications: the mobile phase was composed of water and acetonitrile containing $0.05 \%$ trifluoroacetic acid and run in an acetonitrile gradient of $40-80 \%$ over $22 \mathrm{~min}$ at $0.7 \mathrm{~mL} / \mathrm{min}$. CFZ was detected with a UV detector at a wavelength of $210 \mathrm{~nm}$.

The TA content in CFZ-pTA was estimated by bicinchoninic acid (BCA) assay (Pierce ${ }^{\circledR}$ BCA assay kit). CFZ-pTA $0.1 \mathrm{mg}$ was suspended in $200 \mu \mathrm{L}$ of $0.05 \mathrm{~N} \mathrm{HCl}$ to dissolve TA. The $\mathrm{BCA}$ reagent was mixed with the sample in $8: 1 \mathrm{v} / \mathrm{v}$ ratio at $37{ }^{\circ} \mathrm{C}$ for $30 \mathrm{~min}$. The absorbance of the solution was read at $570 \mathrm{~nm}$ by a SpectraMax M3 microplate reader (Molecular Device, Sunnyvale, CA, USA). CFZ solution at an equivalent concentration was treated same way, and the absorbance was subtracted from the reading of CFZ-pTA. The difference was compared to a calibration curve drawn with TA to determine the TA concentration in the sample.

\section{Albumin content in CFZ-pTA-alb}

The albumin content in CFZ-pTA-alb was determined by sodium dodecyl sulfate polyacrylamide gel electrophoresis (SDS-PAGE). CFZ-pTA-alb with a premeasured mass or standard albumin solutions were prepared in Laemmli buffer containing $\beta$-mercaptoethanol and heated at $95{ }^{\circ} \mathrm{C}$ for $5 \mathrm{~min}$. The samples were resolved on a 12\% SDS-PAGE run at $120 \mathrm{~V}$ for 30 min. After staining with QC Colloidal Coomassie Stain and imaged with Azure c300 (Dublin, CA, USA), the band intensity was analyzed by densitometry (AzureSpot Analysis Software). The albumin content was determined by comparing the band intensities of CFZ-pTA-alb samples and standard albumin solutions.

\section{Size stability}

CFZ-pTA or CFZ-pTA-alb (at a concentration equivalent to CFZ $60 \mu \mathrm{g} / \mathrm{mL}, \mathrm{n}=3$ per group) were incubated in $50 \%$ fetal bovine serum (FBS) at $37^{\circ} \mathrm{C}$ for $24 \mathrm{~h}$. The suspensions were sampled periodically to measure their particle size by the Zetasizer.

\section{In vitro CFZ release kinetics}

CFZ-pTA or CFZ-pTA equivalent to $10 \mu \mathrm{g}$ of CFZ were suspended in $0.25 \mathrm{~mL}$ of $10 \%$ PEG dimethylacrylate (PEGDA, $3400 \mathrm{Da}$ ) solution in PBS. The suspensions were illuminated under UV $(365 \mathrm{~nm})$ for $10 \mathrm{~min}$ in the presence of $25 \mu \mathrm{L}$ of irgacure solution $(20 \% \mathrm{w} / \mathrm{v}$ in methanol) to crosslink PEGDA. The crosslinked PEGDA matrix was briefly rinsed with water to remove free particles and immersed in $1 \mathrm{~mL}$ of RPMI-1640 medium supplemented with 10\% FBS as a release medium ( $n=3$ per group). The matrix was then incubated at $37^{\circ} \mathrm{C}$ on an orbital shaker, and the release medium was completely removed for HPLC analysis and replaced with 1 $\mathrm{mL}$ of fresh medium at predetermined time points. 


\section{Cytotoxicity of CFZ}

B16F10 (derived from murine melanoma; ATCC, Manassas, VA, USA) or HCC-1937 (derived from human triple negative breast cancer; ATCC, Manassas, VA, USA) were grown in RPMI 1640 or DMEM medium, respectively, supplemented with 10\% FBS and penicillin (100 $\mathrm{IU} / \mathrm{mL})$ and streptomycin $(100 \mu \mathrm{g} / \mathrm{mL})$. Cells were seeded in a 96 well plate at a density of 4,000 cells per well. After $24 \mathrm{~h}$ incubation, the culture medium was replaced with fresh medium containing CFZ (as a stock solution in DMSO), CFZ-pTA or CFZ-pTA-alb. The cells were subject to either continuous treatment (in drug-containing media at concentrations equivalent to CFZ $10-400 \mathrm{nM}$ for $72 \mathrm{~h}$ ) or pulse treatment (in drug-containing media at concentrations equivalent to CFZ 50 - $800 \mathrm{nM}$ for 2 - $24 \mathrm{~h}$, followed by washout and additional incubation in drug-free medium up to $72 \mathrm{~h}$ ). Cell viability was estimated by the MTT (3-(4,5-dimethylthiazol2-yl)-2,5-diphenyltetrazolium bromide) assay. Culture medium was replaced with $100 \mu \mathrm{L}$ of fresh medium and $15 \mu \mathrm{L}$ of MTT solution $(5 \mathrm{mg} / \mathrm{mL})$, and cells were incubated for $4 \mathrm{~h}$. The stop/solubilizing solution was added to dissolve formazan crystals, and the absorbance was read at the wavelength of $562 \mathrm{~nm}$ by the SpectraMax M3 microplate reader. The cell viability was calculated by normalizing the measured absorbance to that of control cells that did not receive treatments.

The cytotoxicity of CFZ was also measured on splenocytes. The spleen was freshly harvested from a male C57BL/6 mouse, cut into pieces, and filtered through $70 \mu \mathrm{m}$ and $40 \mu \mathrm{m}$ cell strainers sequentially to obtain a single cell suspension. The cell suspension was incubated with $1 \mathrm{~mL}$ ammonium-chloride-potassium (ACK) lysis buffer for $1 \mathrm{~min}$ to remove red blood cells. The splenocytes, suspended in RPMI 1640 medium supplemented with $10 \%$ FBS, penicillin $(100 \mathrm{IU} / \mathrm{mL})$ and streptomycin $(100 \mu \mathrm{g} / \mathrm{mL})$, were seeded at 200,000 cells per well in a 96 well plate and treated with CFZ solutions for $24 \mathrm{~h}$ or $2.4 \mathrm{~h}$ with additional $21.6 \mathrm{~h}$ incubation in drug-free medium. Cell viability was measured as described above.

\section{In vitro metabolic stability of CFZ}

Metabolic stability of CFZ in different formulations (CFZ-CD, CFZ dissolved in $10 \mathrm{mM}$ citrate buffer ( $\mathrm{pH} 3.1$ ) with 20\% (w/v) 2-hydroxypropyl- $\beta$-cyclodextrin), ${ }^{2}$ CFZ-pTA and CFZpTA-alb) was measured in whole blood. The blood was collected from C57BL/6 male mice and stored in a heparinized tube on ice. CFZ formulations were added to the cold blood at a final concentration of $67 \mu \mathrm{M}\left(\mathrm{n}=3\right.$ per group) and incubated at $37^{\circ} \mathrm{C}$ for $30 \mathrm{~min}$. The blood sample was mixed with $200 \mu \mathrm{L}$ of $5 \%$ Triton-X 100 and vortexed for $10 \mathrm{~min}$. To this mixture, $600 \mu \mathrm{L}$ of acetonitrile was added, bath-sonicated for $10 \mathrm{~min}$, and centrifuged at $4500 \mathrm{rcf}$ for $30 \mathrm{~min}$ to remove precipitated proteins. The supernatant was analyzed by HPLC. ${ }^{1}$ A calibration standard curve was prepared with CFZ doped in blood at final concentrations of $4-278 \mu \mathrm{M}$ and treated in the same way as the samples immediately.

\section{Cellular uptake of CFZ-pTA or CFZ-pTA-alb}

Fluorescently-labeled CFZ-pTA (CFZ*-pTA) or CFZ-pTA-alb (CFZ*-pTA-alb) were prepared by adding DiI in the CFZ/TA mixture at a concentration of $0.5 \mathrm{wt} \%$. The amount of incorporated DiI was determined by measuring the fluorescence intensity $\left(\lambda_{\mathrm{ex}} / \lambda_{\mathrm{em}}: 549 \mathrm{~nm} / 565 \mathrm{~nm}\right)$ of DiI after dissolving nanocapsules in acetonitrile. B16F10 or HCC 1937 cells were seeded in a $35 \mathrm{~mm}$ glass bottom dish with a $14 \mathrm{~mm}$ micro-well, at a density of 300,000 cells per dish. After $24 \mathrm{~h}$, the medium was replaced with $1 \mathrm{~mL}$ of fresh serum-supplemented medium containing CFZ*-pTA, CFZ*-pTAalb (particle concentration: $100 \mu \mathrm{g} / \mathrm{mL}$ ), or free DiI, at equivalent fluorescence intensity. After 2 or 4 
$\mathrm{h}$ incubation with the treatments, cells were rinsed with PBS twice followed by fixation with 4\% paraformaldehyde for $10 \mathrm{~min}$. Cells were incubated with Hoechst $33342(5 \mu \mathrm{g} / \mathrm{mL})$ for $5 \mathrm{~min}$ for nuclei staining. After rinsing, cells were imaged with a Nikon-A1R confocal microscope (Nikon America Inc., NY, USA). Cell nuclei were detected with $\lambda_{\mathrm{ex}} / \lambda_{\mathrm{em}}$ of $407 \mathrm{~nm} / 450 \mathrm{~nm}$, and fluorescent nanocapsules with $\lambda_{\mathrm{ex}} / \lambda_{\mathrm{em}}$ of $561 \mathrm{~nm} / 595 \mathrm{~nm}$.

\section{Protein-capturing ability of CFZ-pTA-alb}

B16F10 cells were treated with $10 \mu \mathrm{M}$ CFZ solution in serum-free RPMI 1640 medium (supplemented with penicillin $100 \mathrm{IU} / \mathrm{mL}$ and streptomycin $100 \mu \mathrm{g} / \mathrm{mL}$ ) for $48 \mathrm{~h}$. The cells were centrifuged at $300 \mathrm{rcf}$ for $5 \mathrm{~min}$ to separate soluble protein antigens and DAMPs released from dying cells. CFZ-pTA-alb was incubated in the collected supernatant at a NP concentration of 1 $\mathrm{mg} / \mathrm{mL}$ for $2 \mathrm{~h}$ at $37^{\circ} \mathrm{C}$ with rotation. The particles were centrifuged at $16,100 \mathrm{rcf}$ for $20 \mathrm{~min}$ at 4 ${ }^{\circ} \mathrm{C}$, washed with water twice, resuspended in water at a concentration of $4 \mathrm{mg} / \mathrm{mL}$ and analyzed by SDS-PAGE. Protein bands were excised and analyzed by LC-MS/MS according to the method described previously. ${ }^{3}$

\section{CFZ-pTA-alb - dendritic cell interaction}

Bone marrow cells were collected from healthy male C57BL/6 as reported previously. ${ }^{4}$ Mice at the age of 6-8 weeks were sacrificed using $\mathrm{CO}_{2}$ asphyxiation. Using a syringe, the cavities of femur bones were flushed with RPMI 1640 medium containing penicillin/streptomycin. The collected bone marrow was pipetted several times and passed through a $40 \mu \mathrm{m}$ cell strainer to obtain single cell suspension. The cells were collected by centrifugation at $500 \mathrm{rcf}$ for $8 \mathrm{~min}$, treated with ACK buffer, rinsed, and suspended in IMDM medium supplemented with 10\% FBS, penicillin/streptomycin, $20 \mathrm{ng} / \mathrm{mL}$ GM-CSF, and $10 \mathrm{mM}$ $\beta$-mercaptoethanol at a density of $2 \times 10^{6}$ cells per $10 \mathrm{~mL}$ to differentiate into dendritic cells (DCs). Additional medium was supplemented three days later, and the floating and loosely adherent cells were collected by centrifugation on day 6 . The DC phenotype was confirmed by CD11c staining. In a 6-well plate, $10^{5} \mathrm{DCs}$ were cocultured for 4 or $24 \mathrm{~h}$ with $4 \times 10^{5} \mathrm{DiI}-$ labeled B16F10 cells (denoted as *B16F10 cells; DiI stains the whole cell ${ }^{6}$ ), which had been left untreated or treated with blank pTA-alb, CFZ solution or CFZ-pTA-alb (at a concentration equivalent to $10 \mu \mathrm{M} \mathrm{CFZ)} \mathrm{for} 24 \mathrm{~h}$ and rinsed once. The co-cultured cells were collected, resuspended in staining buffer, incubated with Fc block for $5 \mathrm{~min}$, and stained with APC-labeled anti-mouse CD11c antibody to determine the extent of phagocytic uptake of *B16F10 cells by dendritic cells. Separately, the co-cultured cells (with unlabeled B16F10 cells) were stained with APC-labeled anti-mouse CD11c, FITC-labeled anti-mouse CD40 and PE-labeled anti-mouse CD86 antibodies to determine the activation status of DCs. The stained cells were analyzed by flow cytometry (Accuri C6, BD Biosciences, San Jose, CA, USA). Fluorescence-minus-one (FMO) controls were used for compensation and gating. The extent of phagocytosis was expressed as the percentage of $\mathrm{DiI}^{+} \mathrm{CD} 11 \mathrm{c}^{+}$cells per total $\mathrm{CD} 11 \mathrm{c}^{+}$cells. The DC activation was assessed by $\mathrm{CD} 11 \mathrm{c}^{+} \mathrm{CD} 40^{+}$or $\mathrm{CD} 11 \mathrm{c}^{+} \mathrm{CD} 86^{+}$per total $\mathrm{CD} 11 \mathrm{c}^{+}$cells. 


\section{Local administration of CFZ-pTA-alb}

All animal procedures were approved by Purdue Animal Care and Use Committee, in conformity with the NIH guidelines for the care and use of laboratory animals.

\section{Antitumor effect in B16F10 tumors in C57BL/6 mice}

Male C57BL/6 mice (5-6 week old, $20 \mathrm{~g}$ ) were purchased from Envigo (Indianapolis, IN, USA) and acclimatized for 1 week prior to tumor inoculation. One million B16F10 melanoma cells were inoculated subcutaneously to each C57BL/6 mouse in the upper flank of right hind limb. When tumors reached $50-100 \mathrm{~mm}^{3}$ on the average, mice were randomly assigned to 3 groups and treated with an intratumoral injection of $50 \mu \mathrm{L}$ of PBS, CFZ-CD or CFZ-pTAalb (at a dose equivalent to $1.2 \mu \mathrm{g} \mathrm{CFZ).} \mathrm{The} \mathrm{tumor} \mathrm{volume} \mathrm{and} \mathrm{body} \mathrm{weight} \mathrm{were} \mathrm{measured}$ every day. Animals showing $>20 \%$ body weight loss or with tumors greater than $10 \%$ of the body weight were humanely sacrificed prior to the end of the study. The tumor length (L) and width (W) were measured using a digital caliper and the volume (V) was calculated as: V= (L $\left.\times \mathrm{W}^{2}\right) / 2$ ). The specific growth rate of the tumor was calculated as $\Delta \log \mathrm{V} / \Delta \mathrm{t}$ (t: time in days) ${ }^{7}$. The mice were sacrificed at 7 days after the treatment.

B16F10 tumors were collected, cut into small pieces, mechanically disrupted, and filtered through $70 \mu \mathrm{m}$ and $40 \mu \mathrm{m}$ cell strainers sequentially to obtain a single cell suspension. The cell suspension was incubated with $3 \mathrm{~mL}$ of ACK lysis buffer for $1 \mathrm{~min}$ to remove red blood cells. The cells were rinsed with PBS, resuspended in cell staining buffer at a density of $10^{6}$ cells per $100 \mu \mathrm{L}$, incubated with Fc block for $5 \mathrm{~min}$, and stained with PE-labeled anti-mouse CD8a antibody for $1 \mathrm{~h}$ at $4{ }^{\circ} \mathrm{C}$. The stained cells were analyzed by flow cytometry (Accuri C6, BD Biosciences, San Jose, CA).

\section{CFZ retention in B16F10 tumor}

Fifty microliters of CFZ-CD or CFZ-pTA-alb (at a dose equivalent to $1.2 \mu \mathrm{g} \mathrm{CFZ)} \mathrm{were}$ injected intratumorally into $100 \mathrm{~mm}^{3} \mathrm{~B} 16 \mathrm{~F} 10$ tumors inoculated in C57BL/6 mice. Two hours later the mice were sacrificed, blood was collected via cardiac puncture and put in a heparinized tube. Tumors were harvested, washed with PBS and homogenized in cold PBS (pH 7.4) at 100 mg tissue per $400 \mu \mathrm{L}$ with an Omni Tissue Master 125 homogenizer. A $100 \mu \mathrm{L}$ of the tumor homogenate was vortex-mixed with $200 \mu \mathrm{L}$ of $5 \%$ Triton-X 100 for 2 min and then mixed with tert-butyl methyl ether (TBME) $(1800 \mu \mathrm{L})$ containing carfilzomib-d8 (Cayman Chemical, Ann Arbor, MI, USA) as an internal standard $(250 \mathrm{ng} / \mathrm{mL})$ by rotation for $40 \mathrm{~min}$ to extract CFZ. The mixture was centrifuged at 4,500 rcf for $15 \mathrm{~min}$, and the organic layer was separated, transferred to a glass vial, and dried in vacuum. The dried sample was dissolved in $100 \mu \mathrm{L}$ of DMSO, filtered through $0.45 \mu \mathrm{m}$ syringe filter and analyzed by LC-MS/MS (Agilent triple quadrupole mass spectrometer coupled with the Agilent 1200 Rapid Resolution HPLC, operated in a positive ion mode). ${ }^{8}$ A calibration standard curve was prepared with tumor homogenates doped with CFZ at a concentration of $0.99-500 \mathrm{ng} / \mathrm{mL}$ and processed in the same way as the samples. For quantification of CFZ absorbed to the system, $5 \mu \mathrm{L}$ of plasma was mixed with $40 \mu \mathrm{L}$ of acetonitrile, containing $250 \mathrm{ng} / \mathrm{mL}$ carfilzomib-d8 as an internal standard, and made up to $20 \mu \mathrm{L}$ with water. The mixture was vortexed for 5 min then centrifuged at 13,000 $\mathrm{g}$ for $10 \mathrm{~min}$. The supernatant was analyzed by LC-MS/MS. ${ }^{8}$ A calibration standard curve was prepared with plasma doped with CFZ at a concentration of 3.26 to $416.7 \mathrm{ng} / \mathrm{mL}$ and processed in the same way as the samples. 


\section{Effects on remote B16F10 tumors in C57BL/6 mice or athymic nude mice}

C57BL/6 mice were inoculated with $10^{6} \mathrm{~B} 16 \mathrm{~F} 10$ cells subcutaneously in the upper flank of right hind limb. Seven days later, the mice were inoculated with $3 \times 10^{5}$ B16F 10 cells on the contralateral side. When the first tumor on the right side reached $50 \mathrm{~mm}^{3}$ on the average, mice were randomly assigned to 3 groups. Each mouse received an intratumoral injection of $20 \mu \mathrm{L}$ of PBS, CFZ-CD or CFZ-pTA-alb (at a dose equivalent to $60 \mu \mathrm{g} \mathrm{CFZ)} \mathrm{in} \mathrm{the} \mathrm{first} \mathrm{tumor.} \mathrm{The}$ treated tumor and the second inoculation site on the left were monitored every other day. The same procedure was repeated with athymic nude (Foxn $\left.1^{\text {nu }}\right)$ mice.

\section{Anti-tumor effect and tumor immunophenotyping in CT26 tumors in Balb/c mice}

$10^{5} \mathrm{CT} 26$ mouse colon carcinoma cells (ATCC, Manassas, VA, USA) were inoculated subcutaneously in the mammary fat pad of each female Balb/c mouse. When tumors reached 50$100 \mathrm{~mm}^{3}$ on the average, mice were randomly assigned to 3 groups and received an intratumoral injection of $50 \mu \mathrm{L}$ of PBS, CFZ-CD or CFZ-pTA-alb (at a dose equivalent to $1.2 \mu \mathrm{g} \mathrm{CFZ).} \mathrm{The}$ tumor volume and body weight were measured every day for 7 days. A separate group of CT26 tumor-bearing Balb/c mice $\left(3 \times 10^{5} \mathrm{CT} 26\right.$ cells inoculated subcutaneously to the upper flank of the right hind limb) were treated with PBS, CFZ-CD or CFZ-pTA-alb (at a dose equivalent to 60 $\mu \mathrm{g}$ CFZ) and sacrificed at 6 days post treatment. Tumors were digested in $10 \mathrm{~mL}$ of complete RPMI 1640 containing $1 \mathrm{mg} / \mathrm{mL}$ collagenase I for $1-2 \mathrm{~h}$, passed through a $70 \mu \mathrm{m}$ cell strainer to remove large debris, and then pelleted. The samples were treated with $3 \mathrm{~mL}$ ACK buffer for 2 $\mathrm{min}$ at room temperature, rinsed with 10 volumes of PBS, passed through a $70 \mu \mathrm{m}$ cell strainer and incubated with Zombie Violet and Fc block at room temperature in dark for 10 min. BV605labeled anti-mouse CD45 and APC-labeled anti-mouse CD8a antibodies were added to the samples and incubated for $30 \mathrm{~min}$ at $4{ }^{\circ} \mathrm{C}$. The stained cells were rinsed with PBS and resuspended in $1 \mathrm{~mL}$ of $10 \%$ neutral buffered formalin for flow cytometry analysis (BD LSRFortessa, San Jose, CA, USA).

\section{Tumor-specific immunity in CT26 tumors in Balb/c mice}

Female Balb/c mice were inoculated with $3 \times 10^{5} \mathrm{CT} 26$ cells subcutaneously in the upper flank of right hind limb, followed by $10^{5}$ CT26 cells on the left hind limb 7 days later. When tumors on the right limb grew to $\sim 50 \mathrm{~mm}^{3}$, the mice were randomly assigned to 3 groups and treated with an intratumoral injection of $20 \mu \mathrm{L}$ of PBS, CFZ-CD or CFZ-pTA-alb (at a dose equivalent to $60 \mu \mathrm{g} \mathrm{CFZ).} \mathrm{The} \mathrm{tumor} \mathrm{size} \mathrm{was} \mathrm{monitored} \mathrm{for} 22$ days. At sacrifice, the spleens were collected to evaluate the response to AH1 peptide, a CT26-related peptide antigen.

Splenocytes were prepared as described previously, plated at a density of $3 \times 10^{5}$ cells per well in a 96-well plate, and stimulated with $10 \mu \mathrm{g} / \mathrm{mL}$ of AH1 peptide in the presence of $20 \mathrm{ng} / \mathrm{mL}$ of GM-CSF. After $72 \mathrm{~h}$ incubation, the cells were centrifuged at $300 \mathrm{rcf}$ for 5 min to separate a supernatant. The concentration of interferon- $\gamma$ (IFN- $\gamma$ ) in each supernatant was measured by ELISA (Invitrogen, Carlsbad, CA, USA). The IFN- $\gamma$ production from the AH1 peptidechallenged splenocytes was compared with that of the non-challenged cells collected from the same mouse.

\section{Statistical analysis}

Statistical analysis was performed with GraphPad Prism 7 (La Jolla, CA, USA). All in vitro data were analyzed by unpaired two-way t-test, one-way or two-way ANOVA test to determine the difference of means among groups, followed by the recommended multiple 
comparisons tests. In vivo data were analyzed by one-way ANOVA, followed by Tukey's multiple comparisons test unless specified otherwise. The comparison of survival curves was conducted with the Log-rank (Mantel-Cox) test. The p-value was indicated for each comparison. A value of $p<0.005$ was considered statistically significant, and $p$-values between 0.05 and 0.005 were referred as suggestive, according to the recommendation of the American Statistical Association. ${ }^{9}$ 
Table S1. Particle size and zeta potential of NPs (at least $n=4$ independent samples; mean \pm s.d.)

\begin{tabular}{|l|l|l|l|l|}
\hline NPs & $\begin{array}{l}\text { Suspending } \\
\text { medium }\end{array}$ & Z-average $(\mathrm{nm})$ & PDI & $\begin{array}{l}\text { Zeta potential } \\
(\mathrm{mV})\end{array}$ \\
\hline pTA & Phosphate buffer & $174 \pm 32$ & $0.11 \pm 0.01$ & $-26 \pm 4$ \\
\hline \multirow{2}{*}{ CFZ } & Water & $161 \pm 1$ & $0.17 \pm 0.03$ & $17 \pm 8$ \\
\cline { 2 - 5 } & Phosphate buffer & $3473 \pm 1265$ & $0.57 \pm 0.16$ & $-3 \pm 2$ \\
\hline CFZ-pTA & Phosphate buffer & $164 \pm 1$ & $0.16 \pm 0.02$ & $-27 \pm 4$ \\
\hline CFZ-pTA-alb & Phosphate buffer & $179 \pm 6$ & $0.09 \pm 0.01$ & $-21 \pm 3$ \\
\hline
\end{tabular}

Phosphate buffer: $10 \mathrm{mM}, \mathrm{pH} 7.4$ 
Table S2. NP compositions ( $\mathrm{n}=3$ independent samples; mean \pm s.d.)

\begin{tabular}{|l|l|l|l|l|}
\hline & CFZ (\%) & TA (\%) & Fe (\%) & HSA (\%) \\
\hline CFZ-pTA & $51 \pm 1$ & $49 \pm 7$ & $4.6 \pm 0.02$ & - \\
\hline CFZ-pTA-alb & $41 \pm 2$ & not measured & $3.0 \pm 0.0$ & $15 \pm 1$ \\
\hline
\end{tabular}



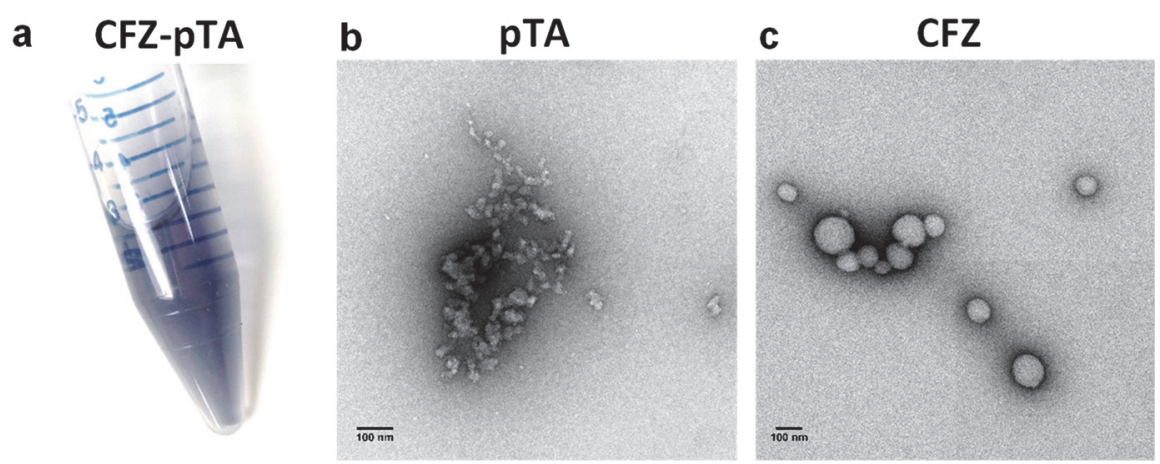

Figure S1. (a) CFZ-pTA suspension with a unique blue color. TEM images of (b) pTA assemblies (without CFZ) and (c) CFZ nanodroplets (without TA and $\mathrm{FeCl}_{3}$ ). 

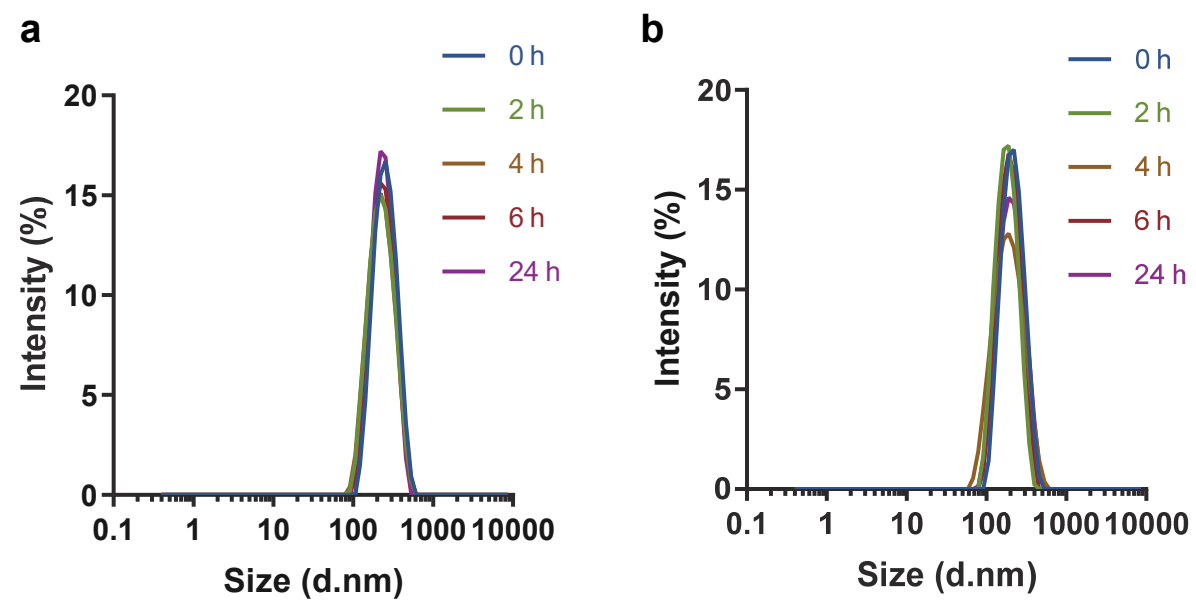

Figure S2. Size distribution of (a) CFZ-pTA and (b) CFZ-pTA-alb, incubated in 50\% FBS at 37 ${ }^{\circ} \mathrm{C}$ for different time periods. Measured by dynamic light scattering. Representative of multiple batches. 


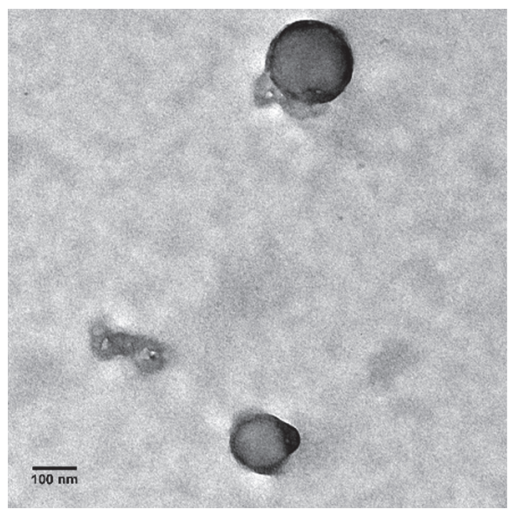

Figure S3. TEM image of CFZ-pTA incubated in 100\% FBS for $24 \mathrm{~h}$. 


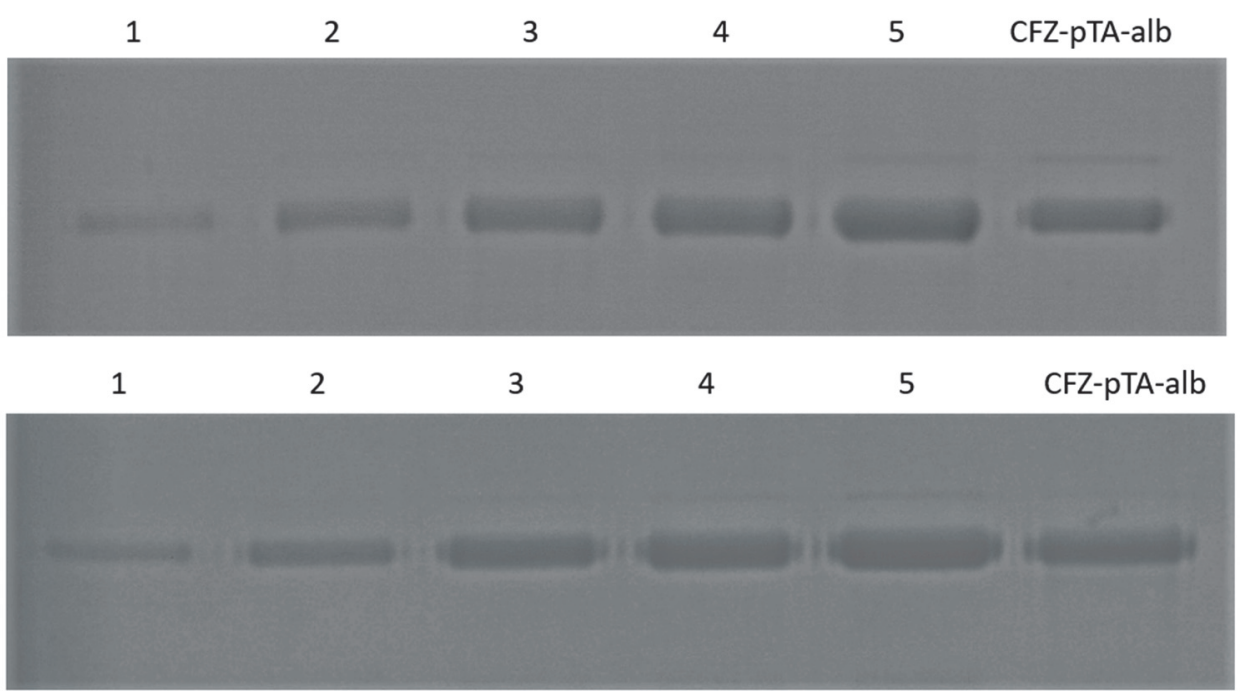

Figure S4. Two representative SDS-PAGE gels used for determination of albumin content in CFZ-pTA-alb. Lanes 1, 2, 3, 4 and 5: 10, 25, 50, 75 and $100 \mu \mathrm{g} / \mathrm{mL}$ albumin. 
a
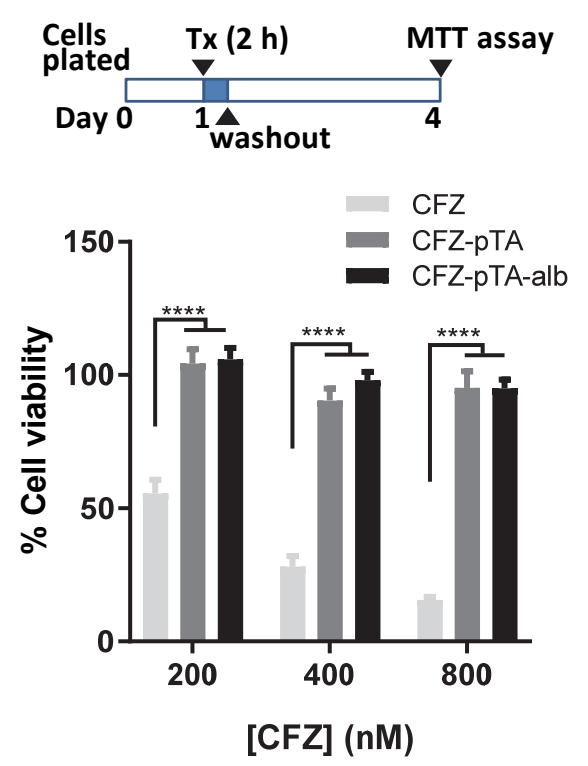

b
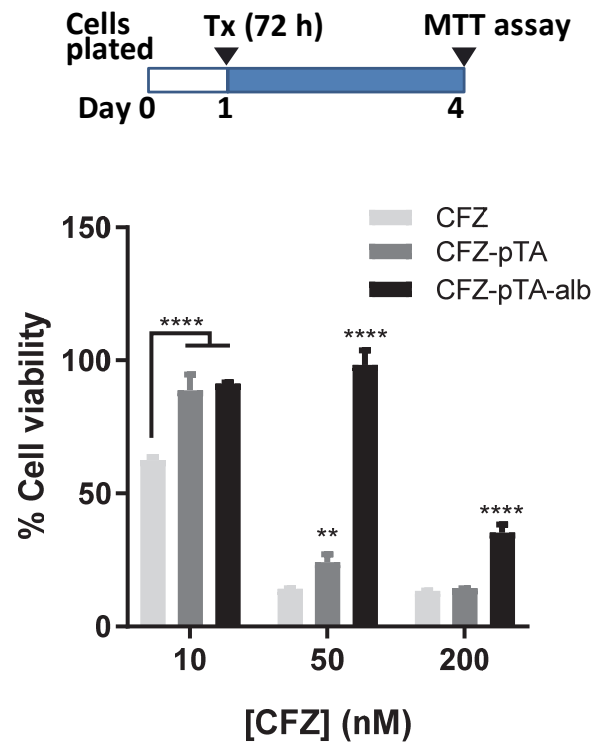

Figure S5. Viability of HCC-1937 cells (a) exposed to CFZ, CFZ-pTA or CFZ-pTA-alb at equivalent CFZ concentrations (200, 400 or $800 \mathrm{nM}$ ) for $2 \mathrm{~h}$, followed by incubation in drug-free medium with the total incubation time of $72 \mathrm{~h}$, or (b) exposed to CFZ, CFZ-pTA or CFZ-pTAalb at equivalent CFZ concentrations $(10,50$ or $200 \mathrm{nM})$ for $72 \mathrm{~h}^{* *}: p<0.01$ and $* * * *: p<$ 0.0001, two-way ANOVA with Dunnett's multiple comparisons test versus CFZ. 


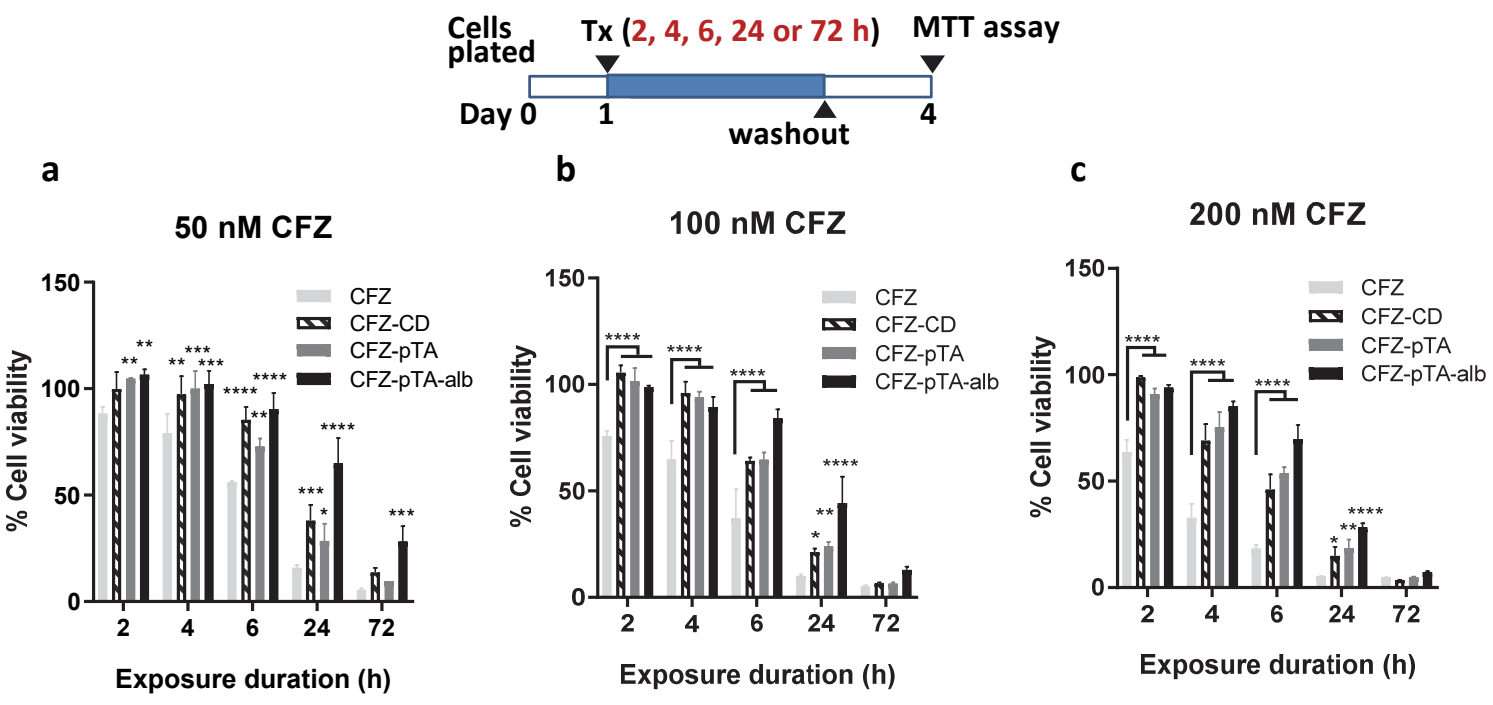

Figure S6. Viability of B16F10 cells exposed to CFZ, CFZ-CD, CFZ-pTA or CFZ-pTA-alb at concentrations equivalent to (a) $50 \mathrm{nM}$, (b) $100 \mathrm{nM}$, or (c) $200 \mathrm{nM}$ of CFZ for 2, 4, 6, 24 or $72 \mathrm{~h}$, followed by incubation in drug-free medium with the total incubation time of $72 \mathrm{~h}$. 


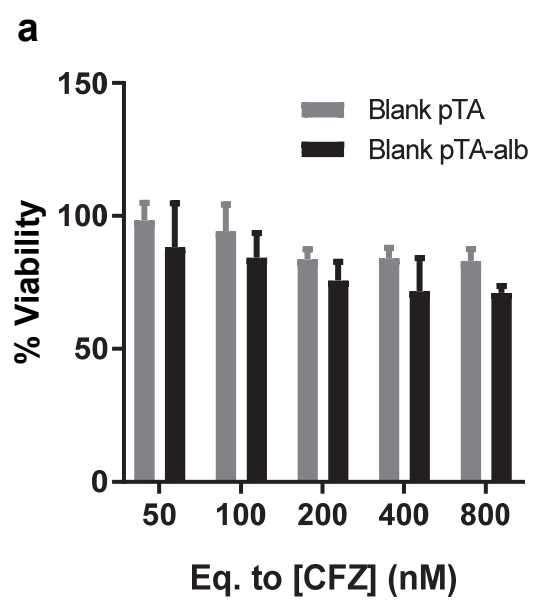

b

\begin{tabular}{|c|c|c|}
\hline $\begin{array}{c}\text { Equivalent } \\
\text { to CFZ } \\
(\mathrm{nM})\end{array}$ & \multicolumn{1}{c}{$\begin{array}{c}\text { Blank pTA } \\
(\mu \mathrm{g} / \mathrm{mL})\end{array}$} & $\begin{array}{c}\text { Blank } \\
\text { pTA-alb } \\
(\mu \mathrm{g} / \mathrm{mL})\end{array}$ \\
\hline 50 & 0.036 & 0.054 \\
\hline 100 & 0.072 & 0.108 \\
\hline 200 & 0.144 & 0.216 \\
\hline 400 & 0.288 & 0.432 \\
\hline 800 & 0.576 & 0.864 \\
\hline
\end{tabular}

Figure S7. (a) Viability of B16F10 cells exposed to blank pTA or blank pTA-alb at concentrations equivalent to their respective contents in corresponding CFZ nanocapsules for 72 h. (b) Concentrations of blank pTA and blank pTA-alb used in cytotoxicity study equivalent to their respective contents in corresponding CFZ nanocapsules. 
a B16F10 cells

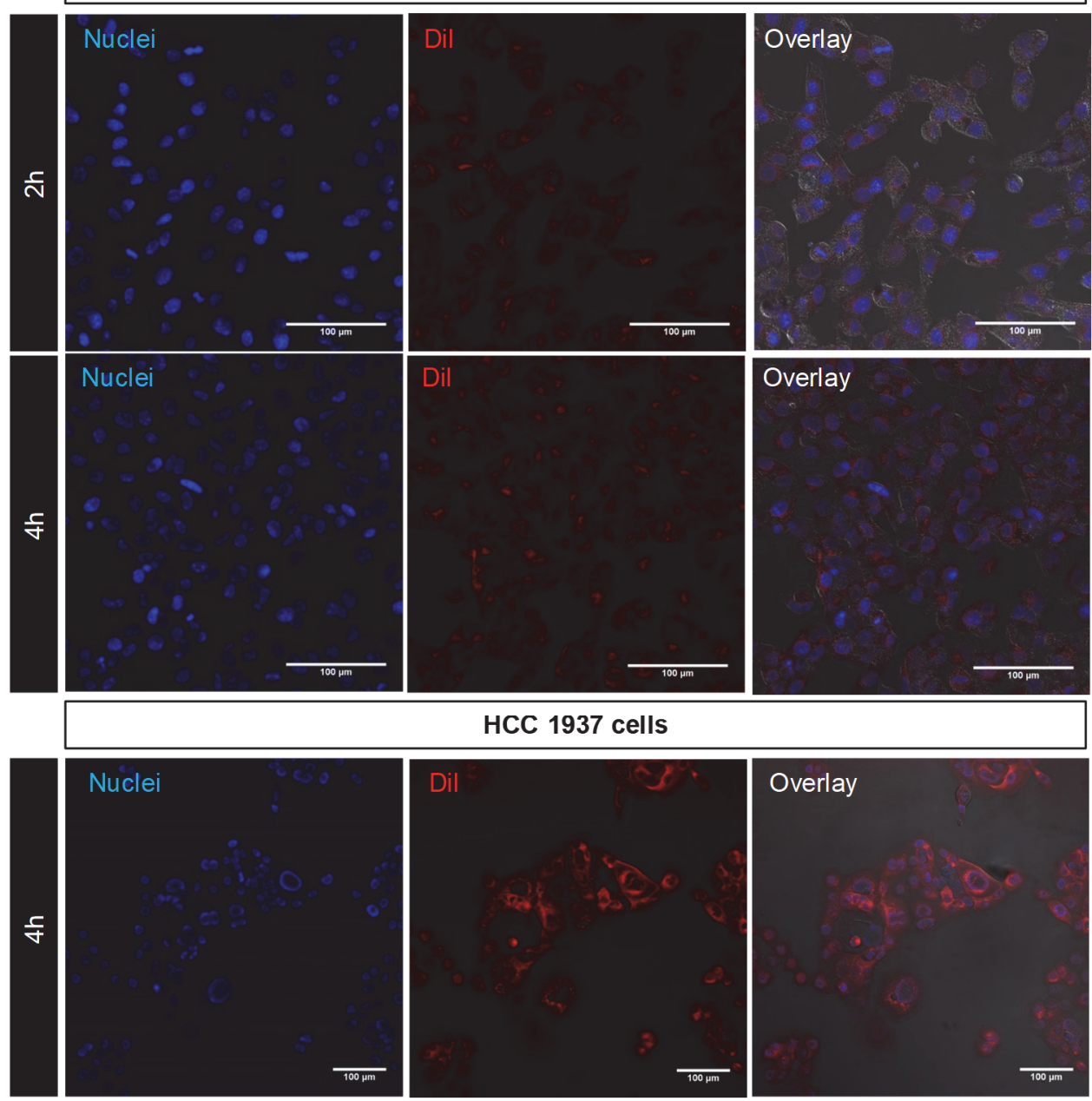


b

B16F10 cells

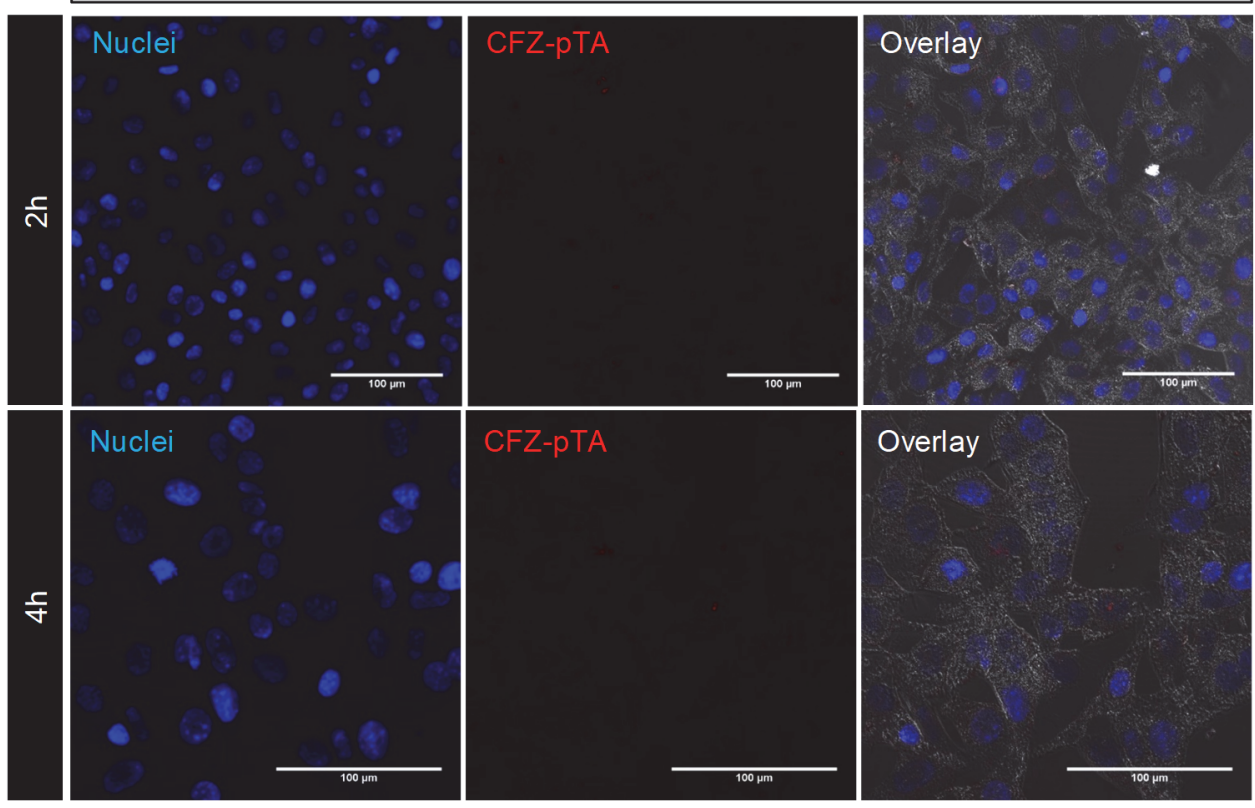

HCC 1937 cells

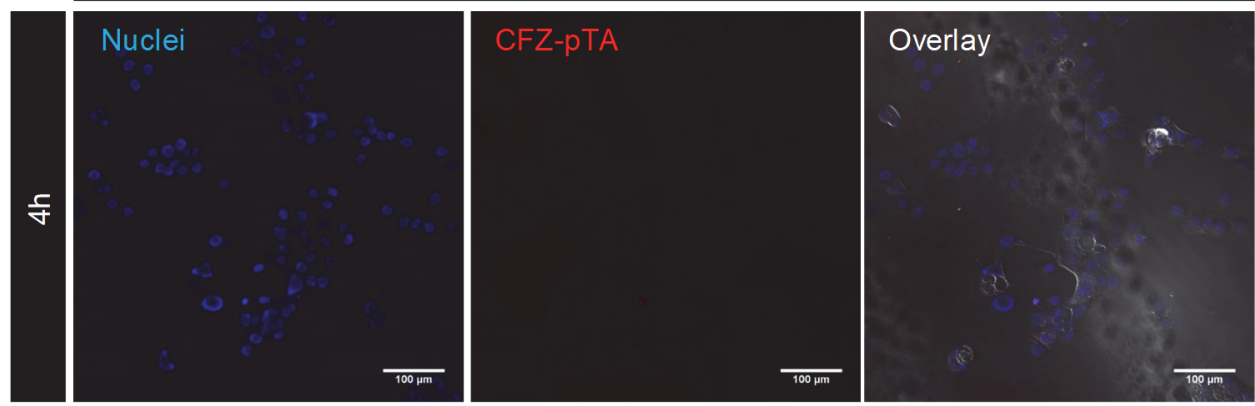



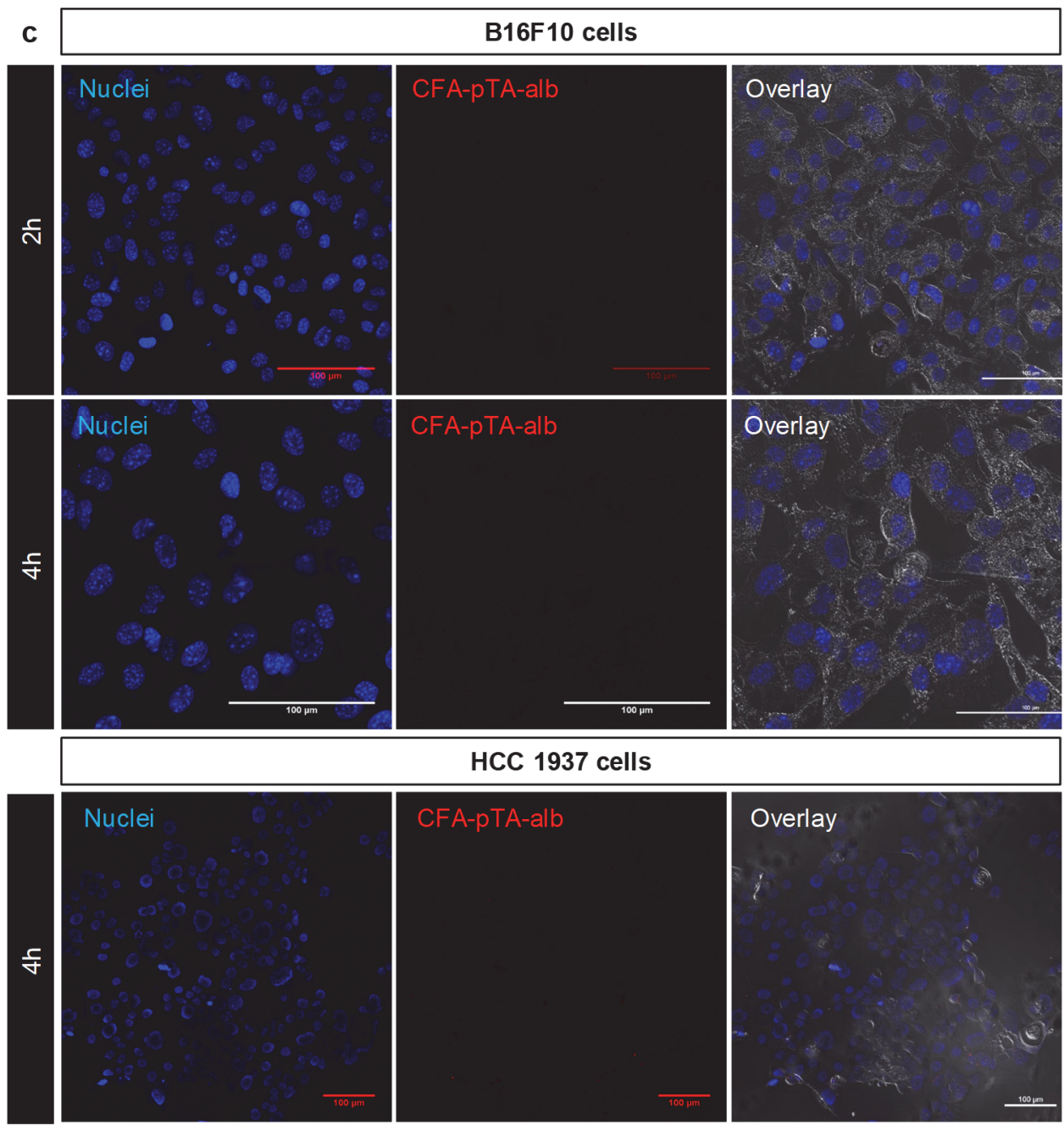

Figure S8. Confocal images of B16F10 and HCC 1937 cells after 2 or 4 h incubation with (a) DiI dye, (b) DiI-labeled CFZ-pTA, or (c) DiI-labeled CFZ-pTA-alb (at equivalent fluorescence intensity). Nanocapsules were given at $0.1 \mathrm{mg} / \mathrm{mL}$. Red: DiI or DiI-labeled CFZ-pTA-alb; blue: nuclei stained with Hoechst 33342. Scale bars: $100 \mu \mathrm{m}$. 

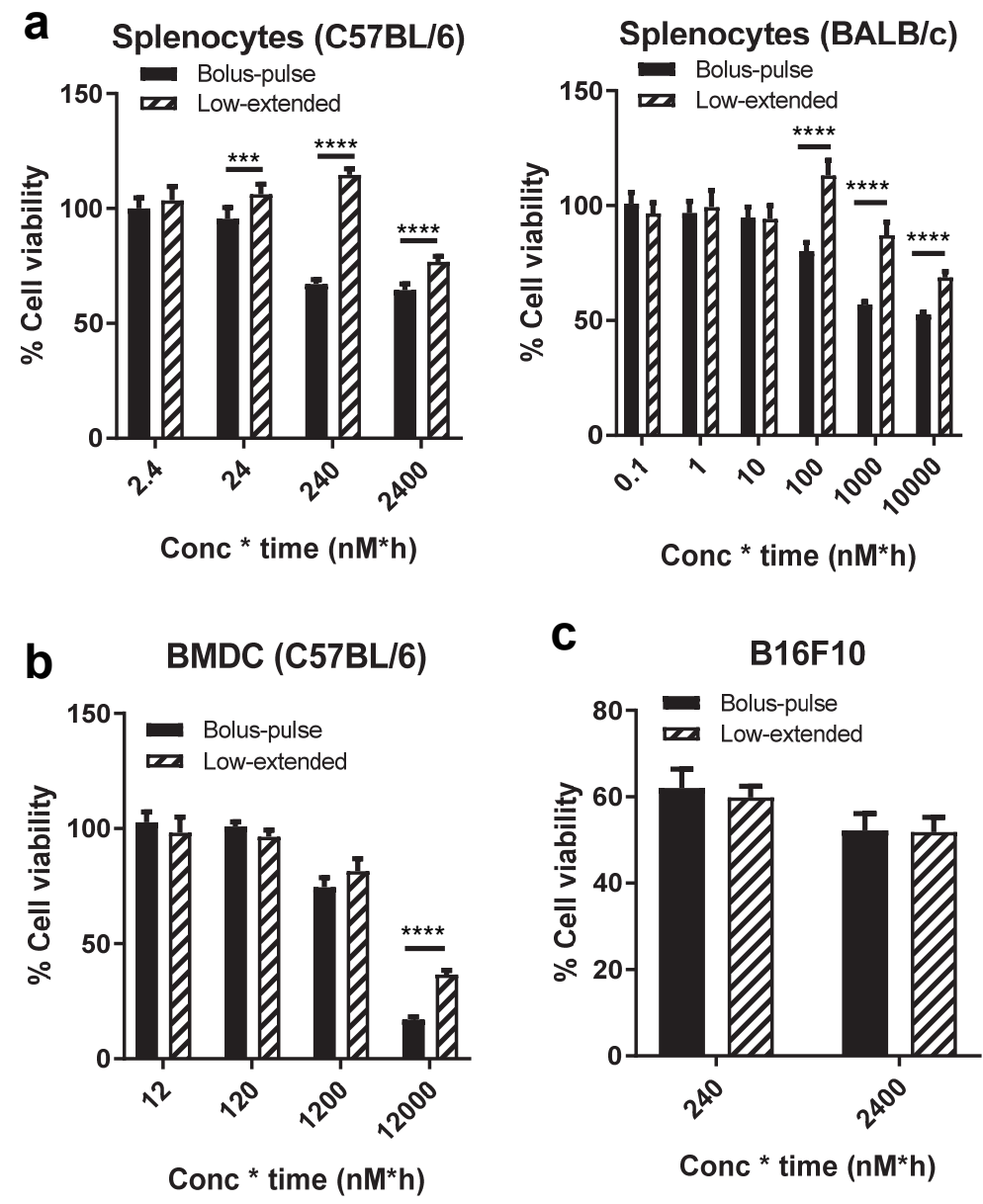

Figure S9. Viability of (a) spleen cells from Balb/c or C57BL/6 mice, (b) dendritic cells derived from C57BL/6 mouse bone marrow, and (c) B16F 10 cells, after bolus-pulse or low-extended treatments. Bolus-pulse: Cells were incubated with CFZ at different CFZ concentrations for $2.4 \mathrm{~h}$ then washed and incubated in drug-free medium for additional $21.6 \mathrm{~h}$ making the total incubation time of $24 \mathrm{~h}$. Low-extended: Cells were incubated with at $1 / 10^{\text {th }} \mathrm{CFZ}$ concentrations for $24 \mathrm{~h}$. Cell viability was measured by the MTT assay at the end of $24 \mathrm{~h}$. \% cell viability was calculated by normalizing to the viability of control cells treated with the equivalent amount of vehicle for the same period of time. $\mathrm{X}$-axis $=\mathrm{CFZ}$ concentration $\times$ exposure time. ${ }^{* *}: p<0.01, * * *: p<$ 0.001 and ${ }^{* * *}: p<0.0001$, two-way ANOVA with Sidak's multiple comparisons test. 


\section{pTA-alb + \\ B16F10 lysate Albumin}

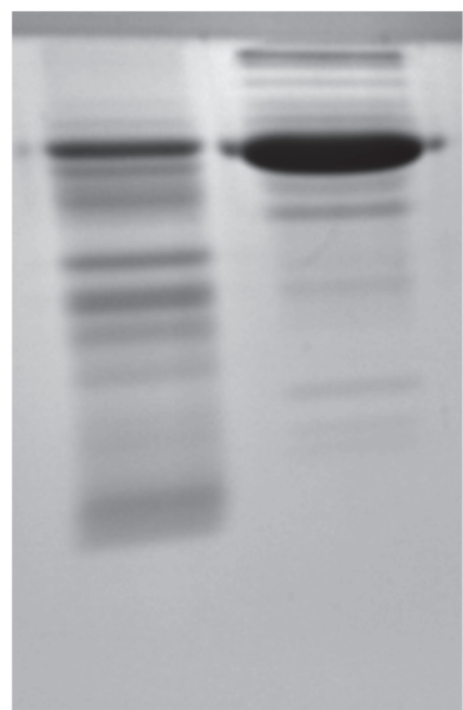

Figure S10. SDS-PAGE gel of pTA-alb incubated in B16F10 cell lysate (B16F10 cells treated with $10 \mu \mathrm{M} \mathrm{CFZ}$ in $10 \%$ FBS containing medium for $24 \mathrm{~h}$ and lysed by 3 cycles of freezing and thawing. Lysate includes both cell debris and medium.) for $2 \mathrm{~h}$ at $37^{\circ} \mathrm{C}$ then rinsed twice with water; Albumin control to locate albumins from pTA-alb particles and FBS. 

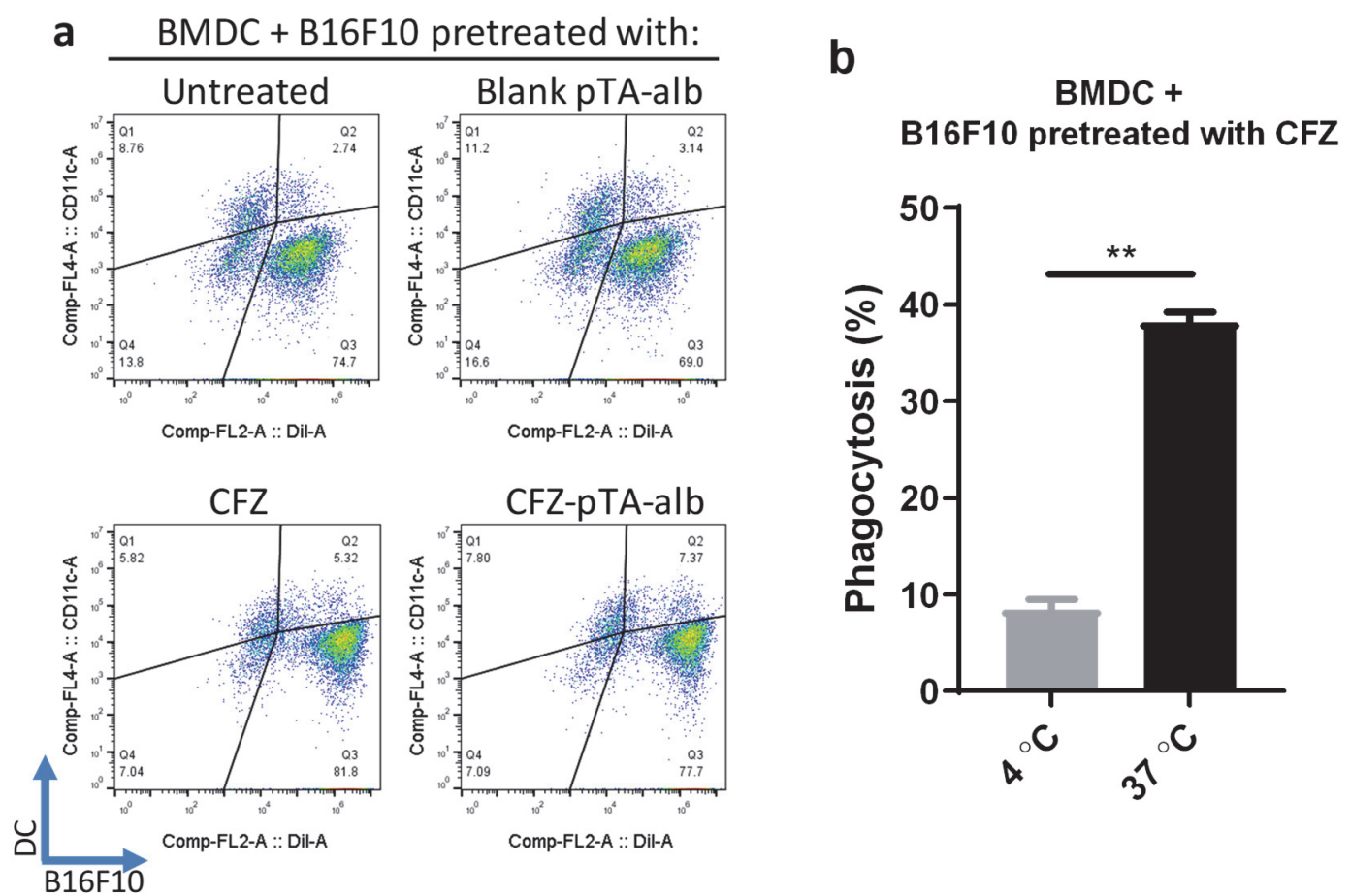

Figure S11. Phagocytosis of B16F10 cells by BMDCs: (a) DiI-stained B16F10 cells were pretreated with blank pTA-alb, CFZ or CFZ-pTA-alb (at a concentration equivalent to $10 \mu \mathrm{M}$ $\mathrm{CFZ}$ ) for $24 \mathrm{~h}$, rinsed once and cocultured with BMDCs for $4 \mathrm{~h}$ at $37^{\circ} \mathrm{C}$. BMDCs were identified with APC-anti mouse CD11c antibody and analyzed by flow cytometry. Representative flow cytometry plots are shown. Upper right quadrant $\left(\mathrm{Q} 2, \mathrm{DiI}^{+} \mathrm{CD} 11 \mathrm{c}^{+}\right.$cells) indicates BMDCs engulfing B16F10 cells (or cell fragments) receiving different treatments. (b) Phagocytosis (\%): fraction of BMDCs engulfing B16F10 cells (pretreated with $10 \mu \mathrm{M} \mathrm{CFZ)} \mathrm{after} 4 \mathrm{~h}$ coculture at 4 ${ }^{\circ} \mathrm{C}$ or $37^{\circ} \mathrm{C}$. ${ }^{* *}: p<0.01$, unpaired two-tailed $t$-test. 
a

BMDC (whole cell) + B16F10 pretreated with:

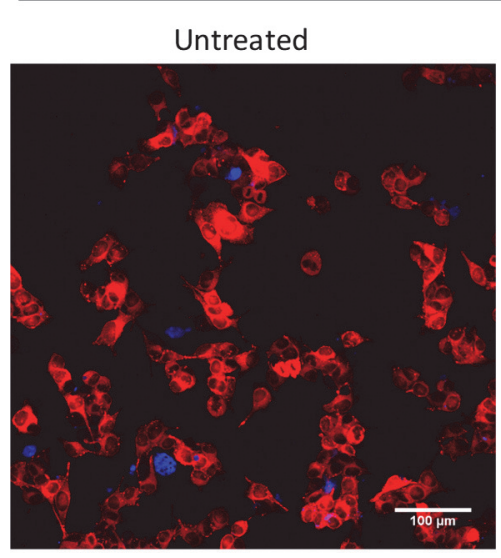

CFZ

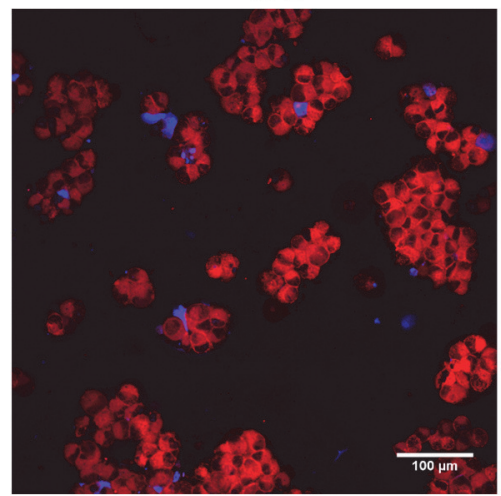

Blank pTA-alb

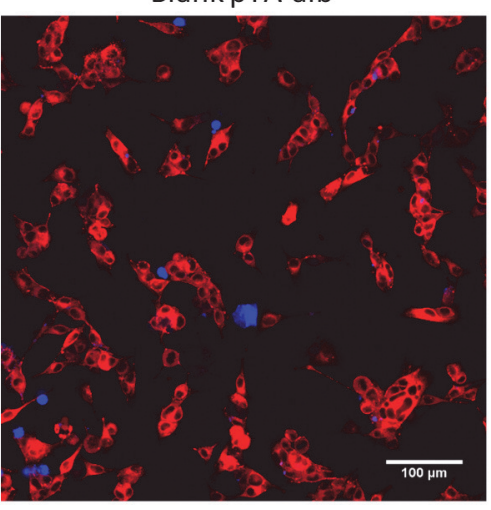

CFZ-pTA-alb

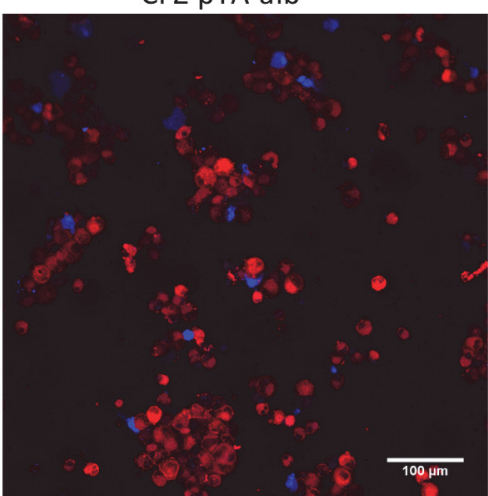

b

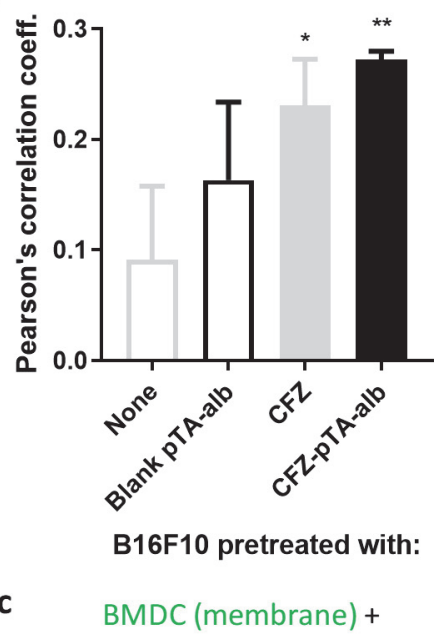

B16F10 pretreated with CFZ-pTA-alb

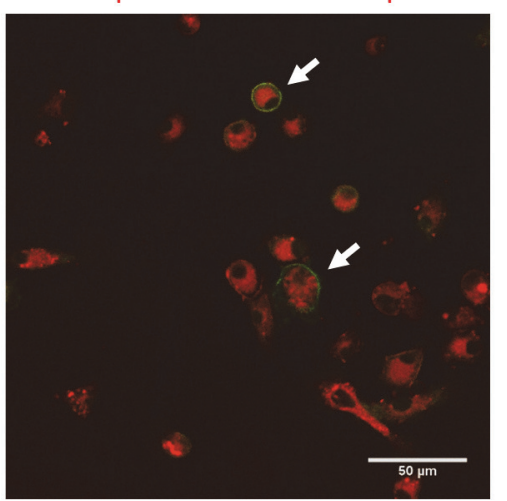

Figure S12. Confocal microscope images of BMDCs engulfing B16F10 cells after 4 h coculture: (a) B16F10 cells and BMDCs were prelabeled with DiI (red) and CellTracker ${ }^{\mathrm{TM}}$ Blue CMAC dye (blue), respectively. Scale bars: $100 \mu \mathrm{m}$. (b) Pearson's correlation coefficients representing colocalization of red and blue signals (i.e., B16F10 cells taken up by BMDCs) in (a), calculated by NIS Elements viewer software. Averages \pm standard deviations of 3-4 images per sample. (c) B16F10 cells were prelabeled with DiI (red), and the surface of BMDCs was stained with FITCanti-mouse CD11c antibody (green). Scale bar: $50 \mu \mathrm{m}$. 
a B16F10 tumor in athymic nude mice

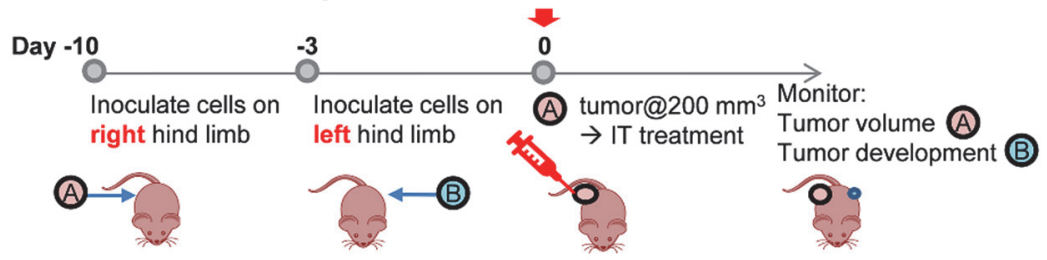

b

A (PBS)

A (CFZ-CD)

A (CFZ-pTA-alb)
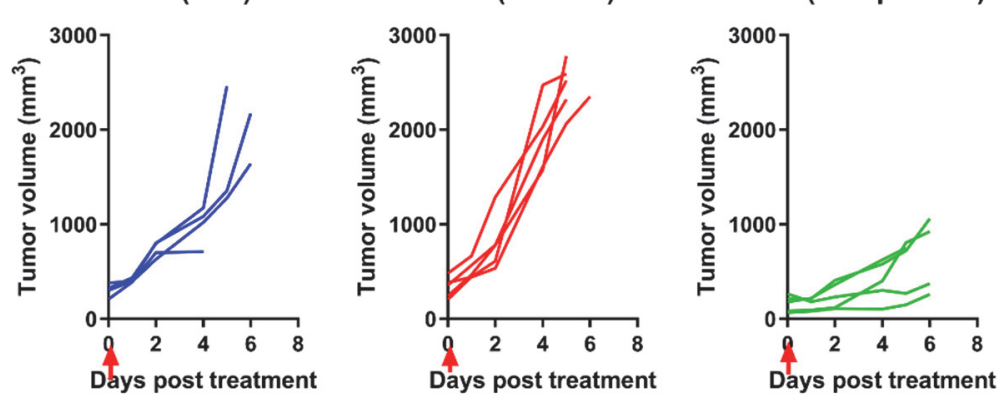

C

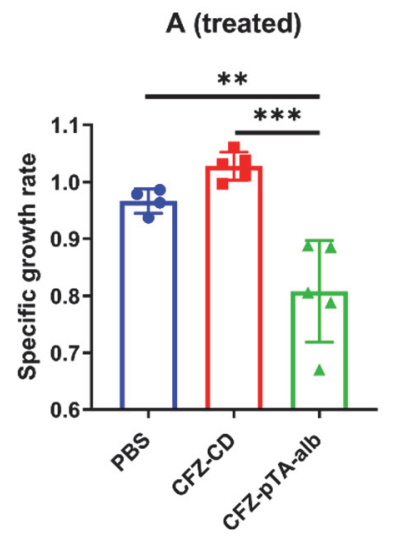

d

B (remote)

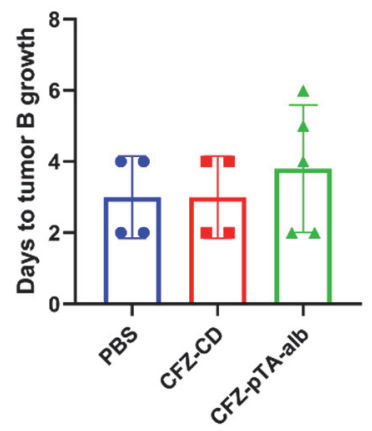

Figure S13. The effect of CFZ-pTA-alb vs. CFZ-CD, administered as a single IT injection at a

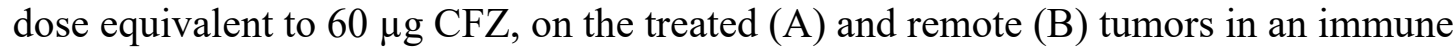
compromised B16F10@athymic nude (Foxn $1^{\text {nu }}$ ) mouse model. (a) Schedule of B16F10 tumor inoculation in athymic nude (Foxn ${ }^{\mathrm{nu}}$ ) mice with deficient $\mathrm{T}$ cell function and treatment injection. (b and c) Antitumor activity in the treated tumor A: (b) Individual growth curves of tumors treated with PBS $(n=4)$, CFZ-CD $(n=4)$ or CFZ-pTA-alb $(n=5)$. Arrow indicates the treatment time. (c) Specific growth rate of treated tumor $(\Delta \log V / \Delta t)$. (d) Days to appearance of tumor B (remote, untreated). ${ }^{* *}: p<0.01$ and ${ }^{* * *} p<0.001$, one-way ANOVA with Tukey's multiple comparisons test. 
Tumor

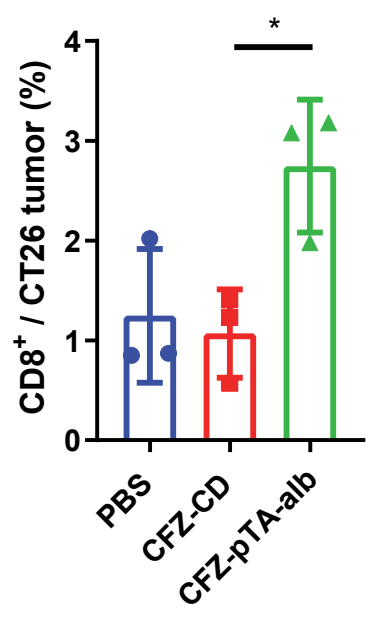

DLN

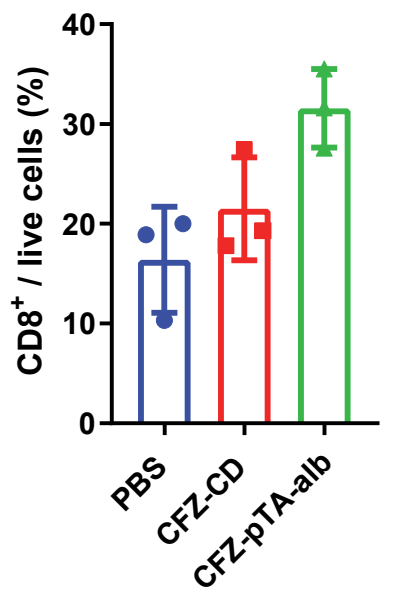

Figure S14. \% $\mathrm{CD} 8^{+} \mathrm{T}$ cells of total live cells in CT26 tumors or draining lymph nodes of mice receiving a single IT injection of CFZ-CD or CFZ-pTA-alb ( $\mathrm{n}=3$ per group) at a dose equivalent to $60 \mu \mathrm{g} \mathrm{CFZ,} 6$ days post treatment. *: $p<0.05$, one-way ANOVA with Tukey's multiple comparisons test. 


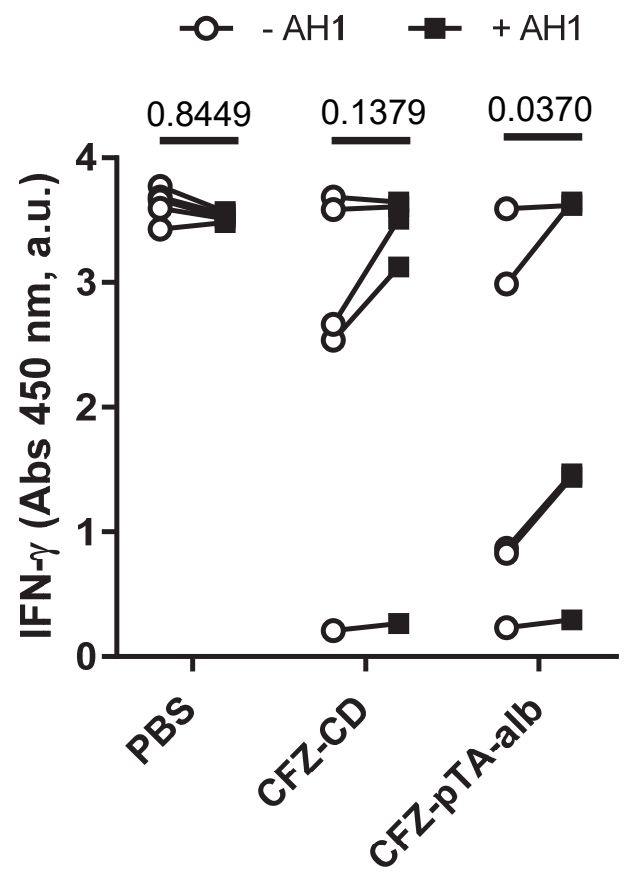

Figure S15. IFN- $\gamma$ secretion from splenocytes of Balb/c mice bearing CT26 tumors with treatments, in response to AH1 peptide. Balb/c mice were inoculated with 300,000 CT26 cells on the right hind limb, followed by 100,000 CT26 cells on the left hind limb 7 days later. Right tumors (tumor A) reaching $50 \mathrm{~mm}^{3}$ were treated by a single IT injection of CFZ-CD, CFZ-pTAalb (a dose equivalent to $60 \mu \mathrm{g}$ CFZ) or PBS ( $n=5$ per group). Splenocytes were harvested on day 22 post-treatment and challenged with AH1 peptide to measure IFN- $\gamma$ secretion. Statistical analysis by repeated measures two-way ANOVA with Sidak's multiple comparisons test. 


\section{References}

(1) Hayes, M. E.; Noble, C. O.; Francis C. Szoka, J. Remote Loading of Sparingly WaterSoluble Drugs into Liposomes. 2014.

(2) Park, J. E.; Chun, S.-E.; Reichel, D.; Park, J.; Min, J. S.; Ryoo, G.; Oh, Y.; Bae, S. K.; Yeo, Y.; Bae, Y.; Lee, W., Novel Polymer Micelle and Nanocrystal Formulations for the Proteasome Inhibitor Drug Carfilzomib: Pharmacokinetic and Pharmacodynamic Studies in Human Lung and Breast Cancer Models. The FASEB Journal 2017, 31, 822.6-822.6.

(3) Hyun, H.; Park, J.; Willis, K.; Park, J. E.; Lyle, L. T.; Lee, W.; Yeo, Y., Surface Modification of Polymer Nanoparticles with Native Albumin for Enhancing Drug Delivery to Solid Tumors. Biomaterials 2018, 180, 206-224.

(4) Pang, L.; Pei, Y.; Uzunalli, G.; Hyun, H.; Lyle, L. T.; Yeo, Y., Surface Modification of Polymeric Nanoparticles with M2pep Peptide for Drug Delivery to Tumor-Associated Macrophages. Pharmaceutical Research 2019, 36, 65.

(5) Creighton, T. E., Protein Structure: A Practical Approach. 2nd ed.; Oxford: New York, 1997; p 383.

(6) Fisher Dil Stain (1,1'-Dioctadecyl-3,3,3',3'-Tetramethylindocarbocyanine Perchlorate ('Dii'; Diic18(3))). https://www.thermofisher.com/order/catalog/product/D282.

(7) Mehrara, E.; Forssell-Aronsson, E.; Ahlman, H.; Bernhardt, P., Specific Growth Rate Versus Doubling Time for Quantitative Characterization of Tumor Growth Rate. Cancer Research 2007, 67, 3970-3975.

(8) Min, J. S.; Kim, J.; Kim, J. H.; Kim, D.; Zheng, Y. F.; Park, J. E.; Lee, W.; Bae, S. K., Quantitative Determination of Carfilzomib in Mouse Plasma by Liquid ChromatographyTandem Mass Spectrometry and Its Application to a Pharmacokinetic Study. Journal of Pharmaceutical and Biomedical Analysis 2017, 146, 341-346.

(9) Wasserstein, R. L.; Schirm, A. L.; Lazar, N. A., Moving to a World Beyond "P < 0.05 ". The American Statistician 2019, 73, 1-19. 